\title{
Humanities-oriented Accents in Teaching Mathematics to Prospective Primary School Teachers
}

\author{
Jordan Tabov ", Iordanka Gortcheva \\ Institute of Mathematics and Informatics at the Bulgarian Academy of Sciences, Bulgaria
}

Copyright $\bigcirc 2016$ by authors, all rights reserved. Authors agree that this article remains permanently open access under the terms of the Creative Commons Attribution License 4.0 International License

\begin{abstract}
Our research includes undergraduate students who major in primary school education. Their academic background is prevailingly in the humanities. This poses specific demands on their mathematics instruction at university. To attract them to their mathematics course and raise its effectiveness, we use a series of activities. Writing assignments intrigue the students, shape their personal mathematical experience, and connect literature with mathematics. Special attention is paid to problem solving in which the mathematical concepts studied are applied. The plots and characters from popular children stories, novels, or movies diversify mathematical problems and make them more likable to the students. This results in significant reduction of mathematics anxiety in the classroom and the students advance uninhibited and motivated. Thus using humanities-oriented accents in representing mathematical ideas successfully complements the teaching of mathematics to prospective primary school teachers. It is also a model to be followed in further teaching practices.
\end{abstract}

Keywords Humanities-oriented Mathematics Education, Prospective Primary School Teachers, Word Problems

\section{Introduction}

Our teaching practice shows that the majority of undergraduate students in primary school education are keen on the humanities. Their inclination in literature, history, or culture is a downside neither for their math education at the university nor for their future teaching career. For these students, the precise formulation of mathematical ideas can be confusing and in some cases leads to mathematics anxiety.

For a long time researchers in mathematics education have been discussing this phenomenon. Analysis of its reasons, forms, and consequences [1-5] helps teachers prevent its emerging and instead, develop students' self-confidence towards mathematics and problem solving.

Hadley and Dorward [6] warn that "Mathematically anxious people steer their lives and careers away from mathematical applications, impacting on their career development and future potential". Even small gaps in curricular mathematics knowledge of prospective primary school teachers may make them insecure and interfere with their teaching practices. For this reason Rayner, Pitsolantis, and Osana [7] examine the relationship between pre-service teachers' mathematics anxiety and their conceptual and procedural knowledge of mathematics. Similar concerns drive Haciomeroglu [8] to search to what extent mathematics anxiety can generate mathematics teaching anxiety.

The World Bank data [9] show that during the last decade most primary school teachers in Europe and the United States have been females. Findings point out that female teachers' mathematics anxiety may affect girls' mathematical achievements [10-11]. Therefore, efforts should be made to avoid such negative effects.

Hardly does a universal recipe exist to prevent or fight mathematics anxiety. Experts in the field recommend that special strategies to support the learners should be devised [12-13]. To get a better idea of our learning environment, we carried out a small survey. It showed that during their primary and middle school period our undergraduate students loved mathematics. If any dislike towards mathematics had emerged, it was most probably rooted in abstract mathematical concepts studied in high school together with boring word problems.

\section{Objectives}

Although it may seem ambitious, our objective is to brush off mathematics anxiety from mathematics classes of prospective primary school teachers. We don't think that it is unachievable since we consider the humanities-oriented background of our undergraduate students a basis for developing knowledge of and interest in mathematics.

Another objective we strive to achieve is to empower our students by developing their problem solving skills. According to Polya [14], acquiring such skills obeys a few rules and is to great extent teachable. Thorndike et al. [15] 
note that "Solving problems in school is for the sake of problem solving in life". Therefore, experience with hard or unusual but practically oriented mathematical problems at university not only raises future teachers' professional training and helps them prepare their pupils for mathematical contests, but also improves their personal decision making abilities.

\section{Methods}

\subsection{Mathematical Writing Assignments}

Mathematical writing assignments have long been used in mathematics education to attract students to mathematics, develop their logical thinking, and improve their reasoning [16-17]. They help them properly use mathematical language, better communicate their mathematical ideas, and write their homework, papers, and projects in a concise, consistent, and ordered manner.

Mathematical writing assignments can show the students that not only is mathematics important for them, but that they are also important for it through their experience, ideas, and achievements. Our request to write their own mathematical autobiographies initially puzzled the prospective primary school teachers. However, they soon realized that their "mathematical past" mattered and was worth being shared. Thus the positive teaching practices during their school math classes could be spread out and the negative ones not be repeated.

Another writing assignment put our students in the shoes of experts on mathematics education. They were to imagine that their little siblings, still not in school, had heard the word number and asked about its meaning. This task was a small introduction to the great art of teaching mathematics. It reminded the students that to answer their pupils' questions, they should add a lot of creativity to their mathematical knowledge.

\subsection{Interpreting Excerpts from Children's Literature}

For our next task we selected several sentences from "Alice's adventures in Wonderland" and asked the future teachers to interpret them in the light of mathematics. Since this Lewis Carroll's book is accessible on the Internet [18], the examples could easily be viewed in the specific context. The students had to express their opinions why the Mock Turtle called the arithmetic operations "Ambition, Distraction, Uglification, and Derision".

The words of Alice: "Well! I've often seen a cat without a grin ... but a grin without a cat! It's the most curious thing I ever saw in my life!" reminded the students of the Cheshire cat's character and in search of their meaning they read the whole Chapter 6 of [18].

Most of the prospective teachers did not know that behind the pseudonym Lewis Carroll was the professional mathematician and college professor C. L. Dodgson who always cared about teaching. The fact that A. A. Milne, the author of Winnie-the-Pooh, had mathematical background also surprised the students. The prominent mathematician G. Polya, who invented the famous problem solving technology, first majored in languages and literature.

\subsection{Word Problems from Mathematical Folklore}

The word problems we offered to the prospective primary school teachers did not require tedious calculations, but a simple idea to be applied. In some cases it was just careful counting. To our surprise, the famous problem about the snail in the well was unknown to them. Our version provided the students with new perspectives on the situation:

\section{Problem 1.}

On a hot summer night in late June, Tiny Snail found itself at the bottom of a 10-meter cylindrical well which was completely dried up. At dawn of July $1^{\text {st }}$ it began its journey up. Every day it ascended two meters and every night it descended one meter.

a) On which date did Tiny Snail reach the rim of the well?

b) There was a critical water level mark painted as a red circle on the inside of the wall, four meters above the bottom. How many times did the snail touch or cross that mark?

c) If Tiny Snail was on a tree trunk and was about to reach the ground, how would you formulate a similar problem?

\subsection{Word Problems by a Famous Bulgarian Writer of Children's Literature}

Elin Pelin, a prominent Bulgarian novelist, mentioned by the notorious historian Rotschild in [19], wrote fiction not only for adult readers, but also stories and poems for children. He also published the children newspaper "Path", in which mathematical story-problems appeared regularly [20]. We used this little-known fact in our classes to make connections between mathematics and the humanities.

The leading character of these stories was Uncle Stanyo, a middle-aged man who moved from a little village to the city. Due to his hard work and wise money spending, he adapted successfully to the urban lifestyle. Uncle Stanyo carried the typical virtues of his time and social standing - a genuine love for family, nature, and knowledge. He was also a great storyteller. His neighbors' children gladly gathered to listen to his stories in which he somehow managed to intertwine mathematical problems. Too lengthy sometimes, these stories made Uncle Stanyo's little buddies attentive listeners who were able to extract the information they needed, not missing the important details. The moral of the stories was always the same: logical thinking, creativity, and mathematical knowledge helped to reach a solution no matter how hard the situation was.

The prospective primary school teachers were impressed 
by the authentic moments from the ordinary people's lives. Through them they entered the world of their grandparents' and great-grandparents' childhood, learning how important and respected mathematical knowledge was. Here is one of these stories:

\section{Problem 2.}

This morning my wife and I headed for the market. As loving grandparents do, we took our grandson Mitko with us to spend the day together. However, he became a pain in the neck: whichever store we stopped by, Mitko always wanted us to buy him a present.

In a grocery store I accidentally saw big scales and asked the seller to check my weight. I was just about to step on the scales when Mitko grabbed my pants:

"Grandpa, I want to be with you on the scales!'

"Let me first weigh myself, buddy. Then I'll weigh you as well."

No matter how hard I tried to persuade my grandson, even by buying him a chocolate - he did not agree to get off the scales... I was forced to give in. I allowed Mitko to weigh with me and the scales showed 111 kilograms. After we got off from them, I called my wife to quickly weigh herself while I was entertaining the little troublemaker. But he caught her skirt and did not drop it until he stepped on the scales again with her. Thus both Mitko and grandma's weight together came exactly to 82 kilograms.

"So you and your wife did not weigh separately, uncle Stanyo?"

"No, we didn't. We barely managed to get together on the scales. Thus both grandma and grandpa, without Mitko, weighed 139 kilograms.

Tell me now, how many kilograms each and every one of the three of us weighs." [20]

This problem showed the future teachers that despite the extended narrative style, its mathematical context was quite similar to some word problems in modern mathematics textbooks.

Another story-problem grabbed the students' imagination with its realistic plot about ship deployment. It reminded them of the arrangement of tokens in a board game:

\section{Problem 3.}

In times of a great war, an admiral commanding a fleet of 24 military ships set forth to confront the enemy. Once out at sea, the admiral arranged the ships in a rectangle, in groups of 3 , so that he got 9 ships on each side of that rectangle.

The enemy's navy soon came into view. Daunted by their number, the admiral immediately sent 4 of his ships back to the military base for help. He remained with 20 ships. In order to deceive the enemy, the commander re-arranged the fleet, keeping the same rectangular form as well as the same number of 9 ships on each side.

The help came soon. The 4 ships that had been sent to the base brought another 4 ships with them. Thus the number of ships in the fleet totaled 28. Again the admiral arranged his ships in the form of a rectangle, 9 ships on each side.

Some time elapsed. The military base sent another 4 military ships to support the fleet, thus raising their numbers to 32 ships. The admiral managed to hide the reinforcement from the enemy, again arranging his fleet in a rectangle, with the same number of 9 ships on each side.

You see, buddies, it was four times that the admiral succeeded in keeping the real number of his ships secret from the enemy. What he only did was keep the same rectangular shape of the arrangement and the same number of ships on each side. How did he manage to do that?

Exploring how the different arrangements occurred, the students figured out that the topics on combinatorics and number theory from their math classes were very helpful. As Problem 3 entertained them a lot, the future teachers suggested that their pupils enact the solutions themselves playing in the schoolyard or on stage. The following story-problem from [20] also fitted these purposes [21]:

\section{Problem 4.}

Once a week Uncle Stanyo went to the market to buy some goodies for his family. On that day he had 10 dollars, all of coins of one cent.

Uncle Stanyo did not want to count the coins before the seller, but just to give the exact amount of money. He decided to challenge his neighbors' children who were playing around, asked his wife to bring ten empty purses, and said:

"Here, children, distribute these 1,000 cents among the ten purses in such a way that whatever sum I need to pay, I can use the purses without counting the coins inside. To make this easier for me, label each purse with the number of cents it contains."

How do you think the children accomplished that task?

In this problem professional mathematicians instantly recognize the concept of binary number system. However, the prospective primary school teachers did not immediately guess to apply it, although number systems are a part of their mathematics curriculum in high school and at university [22-24].

\subsection{Word Problems with Funny Plots and Characters}

To improve the undergraduate students' problem solving skills, we offered them not only such long word problems requiring a lot of time to be read but also shorter problems with funny plots and characters. For example, the next problem used as a main character Witty Peter, a figure from Bulgarian folklore loved by young and old. The problem was given at a Bulgarian national mathematics contest [25]. Without diminishing its mathematical content, Witty Peter's presence in the text made the students more relaxed and receptive to problem formulation: 


\section{Problem 5.}

Witty Peter started a business breeding rabbits. He bought a few female rabbits and borrowed a few male rabbits. Each female had 8 rabbits, all females. Some time after that there was another litter of 5 for each female rabbit, with which Witty Peter's rabbits totaled 2,160.

How many rabbits did he originally buy?

Solving word problems with multiple solutions like Problems 1, 3, and 4, the students learned that their pupils might give different answers, all of which correct. The tinges of humor we used in the next problem helped everybody immerse into the situation and reason on both what has been and has not been said about it:

\section{Problem 6.}

Granny started knitting a scarf. Having knitted 10 palms, she decided to have a nap after each palm knitted. But here is what happened: granny knits one palm, nods off, and kitty unknits two; then she knits another palm, dozes off again, and kitty unknits two more, and so on. When granny noticed that of all her knitting there were only 5 palms left, she drove kitty out of the room.

How many palms could kitty have unknitted? [26]

The word problems and activities represented so far aimed to introduce our vision of attracting a larger audience of students to mathematics as a subject and way of thinking. In the same style we formulated about fifty non-standard mathematical problems and periodically assigned them to the class. Seemingly innocent, they were rich in mathematical ideas and caused a lot of difficulties. However, their entertaining characters and plots made the students laugh at their own mistakes and remember the mathematical context.

\section{Discussion of the Results}

\subsection{Reading and Writing Activities}

In accordance with the ideas of qualitative theory [27], we used triangulation of document analysis of the students' assignments, observations, and interviews. We especially valued the unexpected situations which emerged in our classes and carefully analyzed them.

The mathematical autobiographies revealed that our students' love to mathematics in primary and middle school was due to great extent to the personality of their primary school teacher; their strong dislike of complex computations and preferences to the humanities served as a basis for our word problem design. Before our classes none of the students even supposed that there were math competitions for primary schoolchildren. Thus on the grounds of this introductory assignment we selected our teaching methods.
Reading the future teachers' explanations of the notion of number, we were impressed by their inventiveness. To help little children visualize the idea of number and connect it with counting, a student suggested using their passion to collect buttons, marbles, toy cars, etc. Arranging their prized possessions in groups of two, three, four, etc. provided the children with an opportunity to see, touch, and compare quantities and come to the idea of number on their own.

For the purposes of confidentiality all quoted students in this material will have assumed names. One of them, M11, was not willing to invest much time and effort in explaining the notion of number and approached the task quite practically. As Bulgarian national primary school curriculum reduces the arithmetic operations solely on natural numbers, M11 left the job to imagination, using an analogy with the Cat's grin from “Alice in Wonderland". Here are M11's speculations:

M11: "As a grin does not exist separately in reality, numbers do not exist by themselves either. It would be easier for us if we just try to imagine them. Then we can use them freely without their meaning gnawing at us."

Interpreting Lewis Carroll's excerpts, the undergraduate students reasoned about various aspects of the teaching and learning of mathematics. They found intriguing metaphors of the grin of Cheshire cat:

M17: "To add multi-digit numbers by hand requires a lot of work and even an ambition to accomplish it."

L11: "Performing multiplication is really complicated for the little pupils. It severely strains them, causing sometimes their faces to change unpleasantly. Therefore it can be rightfully called uglification."

L13: "Remainder is linked to the dividend, divisor, and quotient just like the grin is linked to the Cat. As the grin can take us to the Cat, the remainder together with quotient and divisor can lead us to the dividend, if properly calculated. Isn't that Lewis Carroll's idea?"

L3: "The Cat impersonates the pupils' efforts in school. The grin is the results of these efforts. Years later when the pupils graduate from school, only the results will remain."

Putting their thoughts on paper convinced the prospective teachers that it was not a trivial task and as in [18] could quite accurately be called "reeling and writhing".

\subsection{Problem Solving}

Our respect to the students' background in the humanities determined their growing problem solving interest. Their mathematical knowledge, experience, and expertise also grew. The students learned to rely more on themselves and not to neglect their reasoning (Figure 1): 


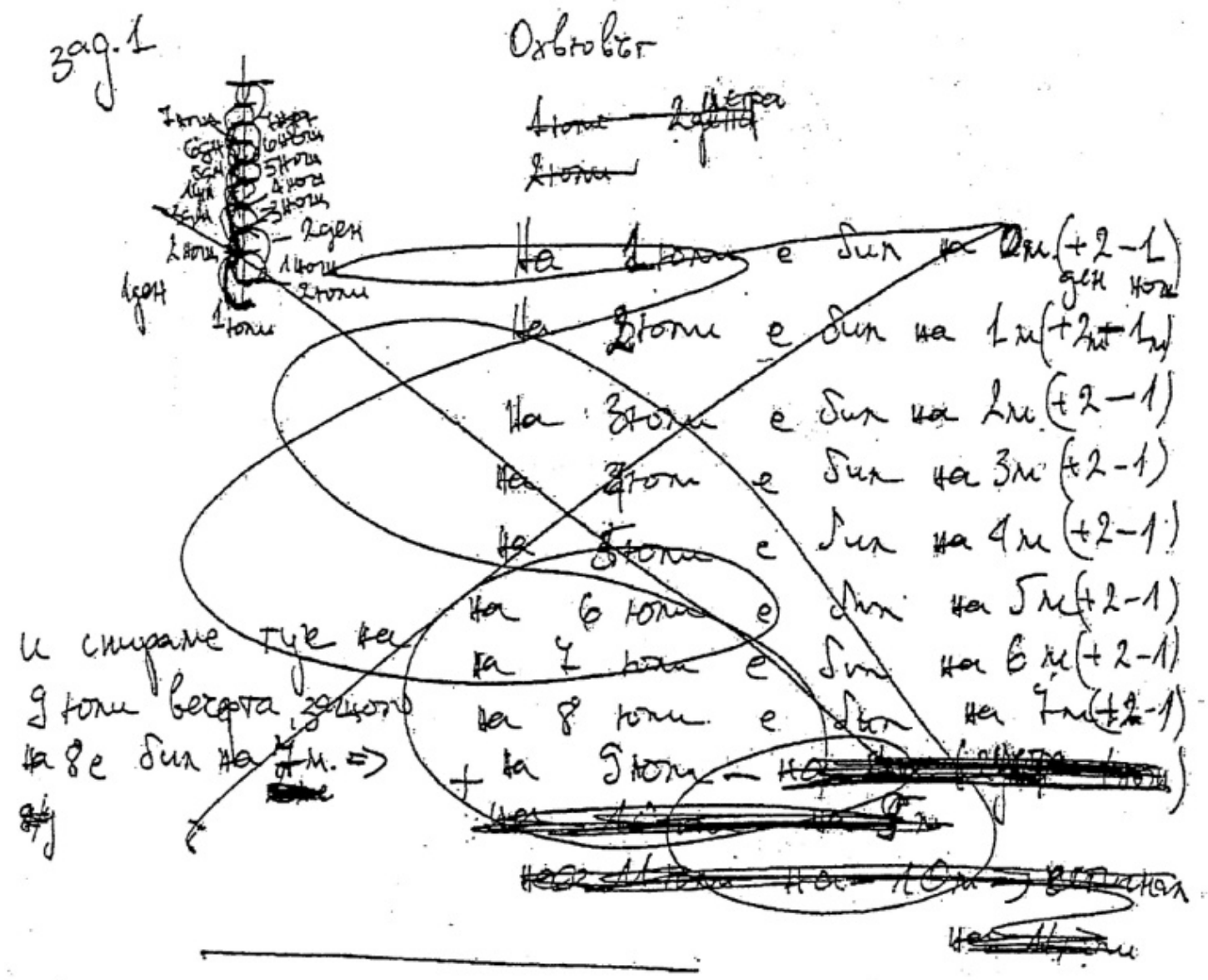

Figure 1. A student's reasoning to Tiny Snail Problem (in Bulgarian) crossed out by its author

Item b) of Problem 1 attracted the students' attention to the continuity of motion (Figure 2). It helped them realize that although Problems 1 and $\mathbf{6}$ differed in plots, they were quite similar. This proved that the bigger the variety of practical situations, the easier it would become for the students to unveil the patterns and solve the problems.

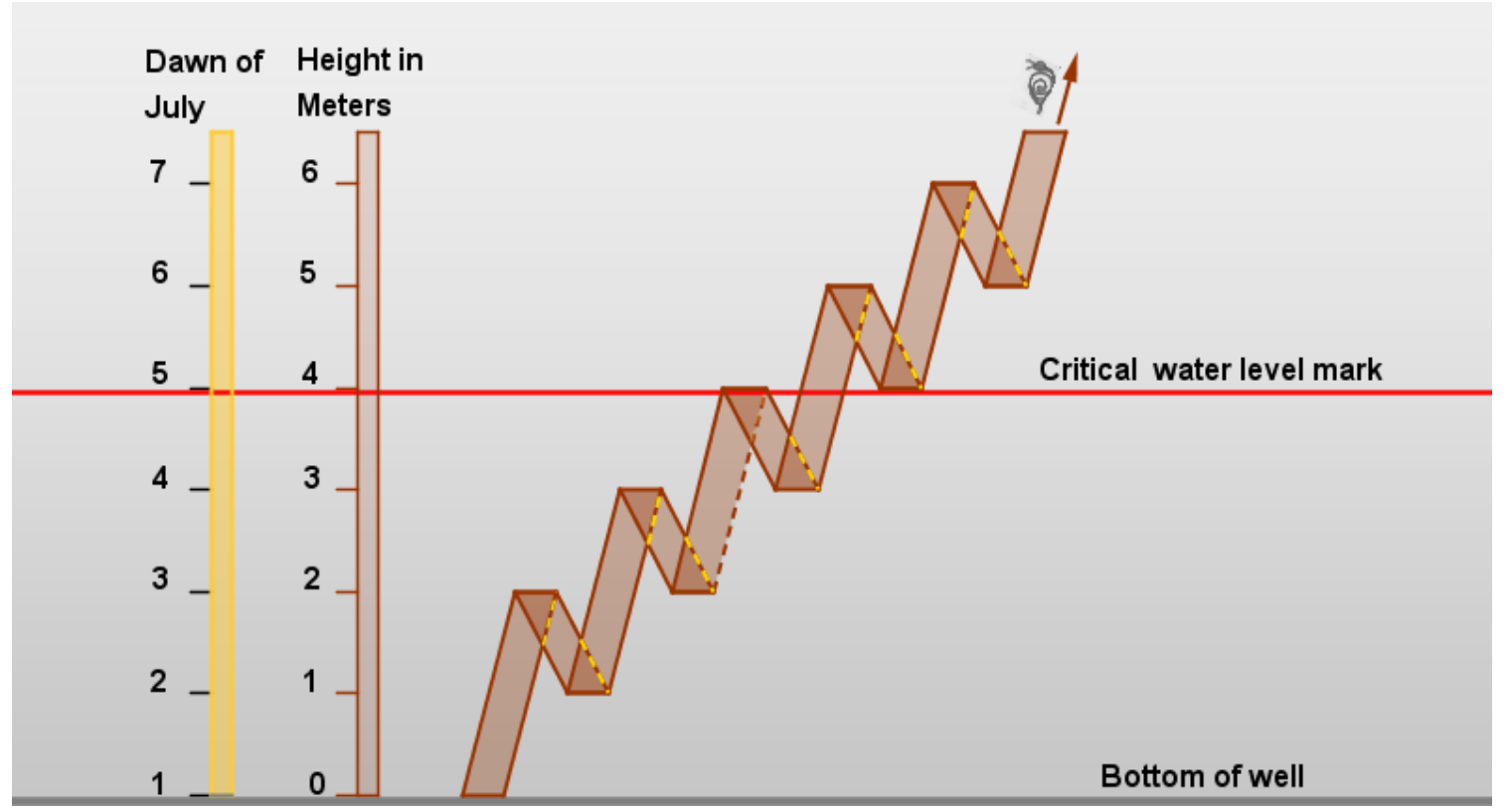

Figure 2. During its journey up and down Tiny Snail crossed or touched the red mark three times (for better visibility, the trace of the snail is shown at a slant) 


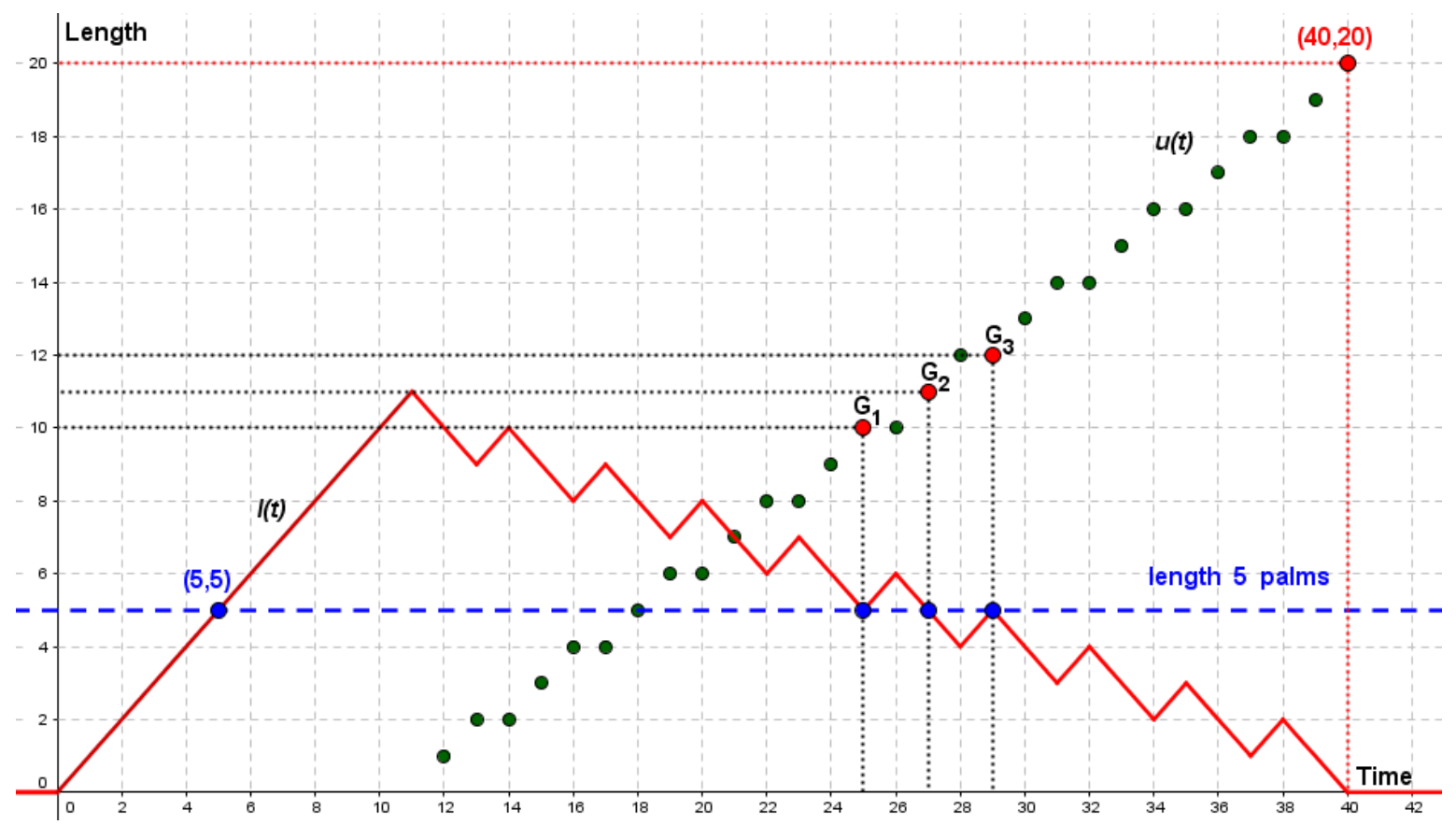

Figure 3. Continuous function $\boldsymbol{l}(\boldsymbol{t})$ represents the current length of the scarf (in palms); discrete function $\boldsymbol{u}(\boldsymbol{t})$-the number of palms unknitted; $\boldsymbol{t}$-time in hours (we assume that both granny and kitty need an hour to knit and unknit one palm of the scarf)

Unlike Problem 1, in Problem 6 the students were to picture and count the number of palms unknitted at a moment of time they had to identify. The graph of function $l(t)$ describing the length of the scarf with respect to time $t$ (used for convenience) showed that the scarf was 5 palms long at more than one moment of time (Figure 3). Since the problem did not state when granny had looked at her knitting, kitty could have unknitted 10, or 11, or even 12 palms.

Except for convenience, using palms as measure of length had another function: it reminded the students of the variety of the existing measurement systems.

When Problem 2 was presented to the students, they approached it in a traditional way by writing a system of three linear equations. Trying to act as primary schoolchildren, they did not use the ordinary variable notations $x, y, z$ but the initials of the characters. The whole class applied a tricky way to solve the system: added the three equations and got the total weight of Uncle Stanyo, his wife, and their grandson Mitko. This was also the approach which the writer Elin Pelin had published in the newspaper.

Unlike Problem 2 which immediately appealed to the students, the next Problem 3 confused them. They found it, if not impossible, then at least not clear enough. Having speculated over it for a while, the class eventually started reading it out loud. We interpreted their spontaneous outburst as a desire to dominate the problem, i.e. to solve it.

The phrase "The admiral arranged the ships in a rectangle, in groups of 3" grabbed the students' attention. They decoded it as a hint to the solution left by the writer to reward the vigilant readers.
We witnessed a remarkable progress in the students' communication ability. Shaping their mathematical ideas in words engaged them in the art of problem posing. The students' opinion was to formulate Problem 3 in a more indicative way. Analyzing the text together, we decided to leave the exciting story unchanged and modify only the question. The students realized that to accomplish the task, they had to have the answer(s) in mind. Although the newly formulated question explicitly suggested an answer quest strategy, it still left enough room for imagination and creativity:

"How did the admiral manage to fulfil his plan, if each time he placed a group of $\boldsymbol{k}$ ships in every vertex and a group of $\boldsymbol{m}$ ships on every side of the rectangle, where $4(\boldsymbol{k}+\boldsymbol{m})$ was the number of the ships in the fleet?"

Combinatorial approach let the students explore various patterns of ship arrangement. Noticing that the same couple of parameters $k$ and $m$ led to different fleet deployment (Figure 4, middle and right), they made their own small discovery and a step ahead in inquiry-based learning.

A wise man once said that the supreme art of war was to subdue the enemy without fighting. One of our students who found the problem almost real made the following comment:

"If the enemy's commander was the admiral's match, he would have hardly been deceived; skillful counting would have revealed the admiral's tricks."

That was the student's understanding of the role of mathematical knowledge in times of hardship. 

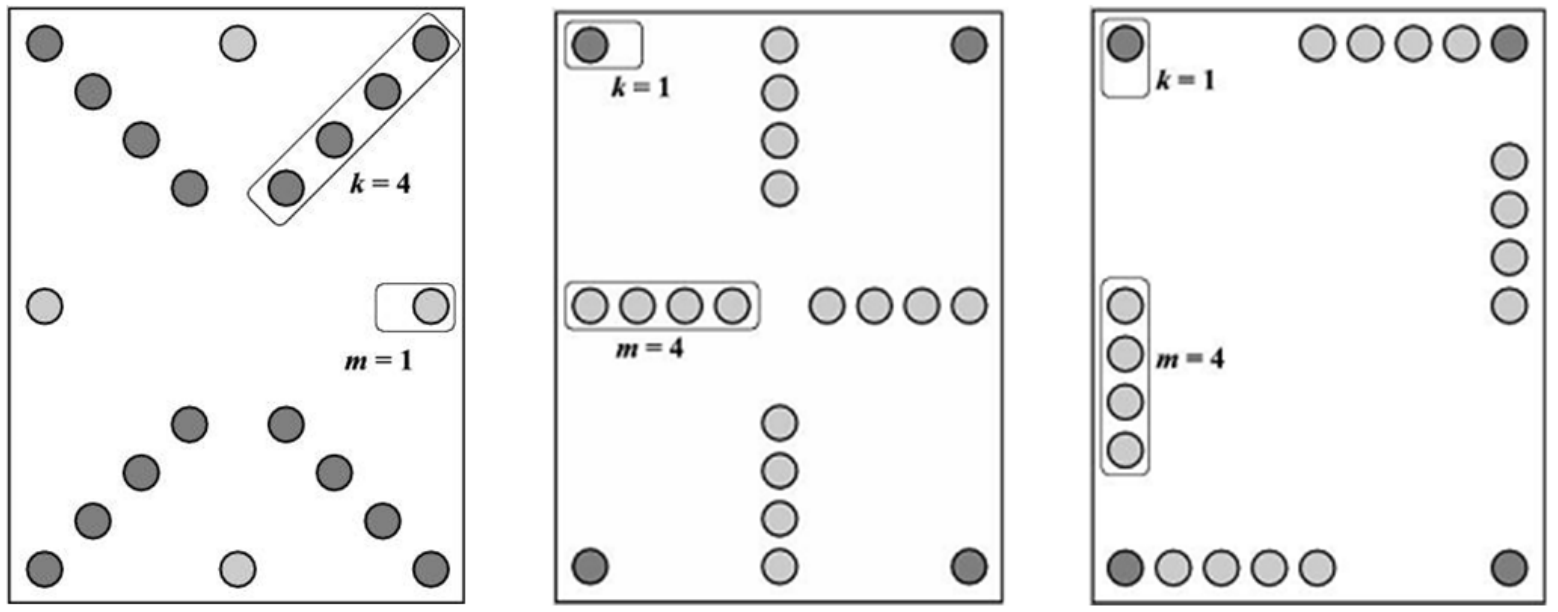

Figure 4. Several arrangements of 20 ships in a rectangle: due to orthogonal projections, 9 ships are visible on each side
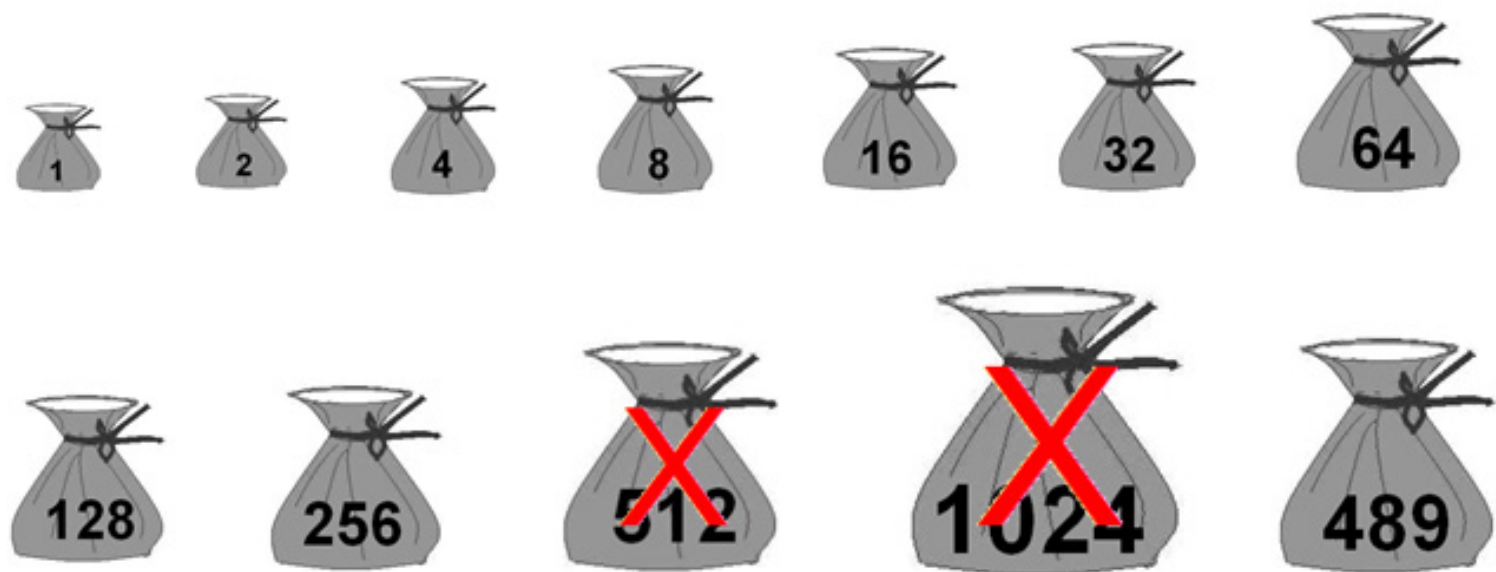

Figure 5. Distributing 1,000 one-cent coins in ten purses to pay any amount of money between 1 and 1,000 cents

According to the prominent philosopher and scientist C. Peirce (1839-1914), "Mathematics has always been more or less a trade. An engineer, or a business company (say, an insurance company), or a buyer (say, of land), or a physicist, finds it suits his purpose to ascertain what the necessary consequences of possible facts would be" [28]. The business and financial nuances embedded in Problems 4 and 5 not only supported these more than a hundred-year-old thoughts but also extremely appealed to the students.

By using the pattern of payments through powers-of-two number of cents, Elin Pelin introduced the concept of binary system to the children. We can only guess whether the writer knew its name, how he made up his story, and why 1,000 one-cent coins had to be distributed in ten purses: if Problem 4 had been posed by a computer scientist, probably 1,023 but not 1,000 cents would have been chosen as numerical data.

What matters in introducing a mathematical concept is "why it works as it does, how it connects to other concepts", as well as if it "can be viewed from different angles" [29]. Accidental or not, Elin Pelin's choice of number led to unexpected results [30] which broadened the students' knowledge. Since not every purse contained an amount of coins equal to a respective power of 2, Basis Representation Theorem [31] could not be applied. Still, any amount of money up to $1,000 \notin$ could be paid through ten purses, but not always by purses containing power-of- 2 cents and sometimes in a twofold way.

The chart in Figure 5 which we used to clarify these details [30], became a tool for exploration. Through it the students found that all amounts of money between $489 \phi$ and $511 \phi$ inclusive could be paid by two different sets of purses: one of the sets contained the $489 \phi$-purse while the other set did not. This was another small discovery and they were very proud of it.

In Problem 5 the popular folk hero Witty Peter once again outwitted his readers. The fact that he had bought only female rabbits brought lots of smiles in the classroom. What we meant was to simplify the problem and the calculations. Everybody quickly divided 2,160 by the product $(8 \cdot 5)$ and obtained the same answer of 54 rabbits. 


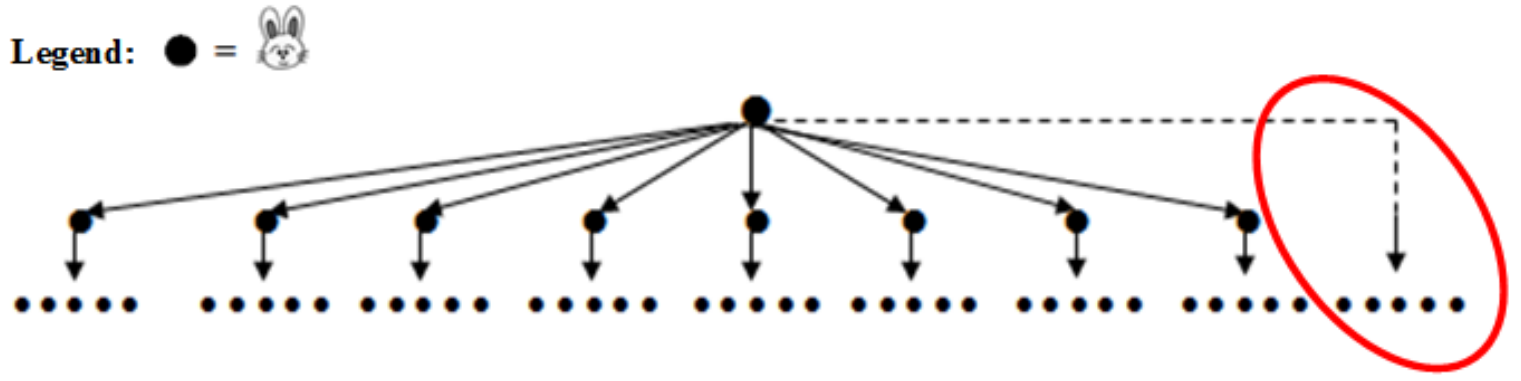

Figure 6. A graph of the two-generation offspring of one female rabbit bought by Witty Peter (the ellipse shows the offspring missed by the students)

It was really hard to convince the class that their result was wrong. To help the students adequately model the situation, we suggested they imagine that each rabbit bought be placed in a separate cage, large enough for her and all her descendants. The tree graph (Figure 6) allowed the students to correctly track and count the descendants: in two generations each cage would house $(1+8+(9 \cdot 5))$ rabbits. Therefore the right answer was the ratio $2,160 \div(9 \cdot 6)=40$.

The students did not anticipate such a significantly better result. Delighted, one of them exclaimed: "Witty Peter was really good at making business. He did deserve his name!"

This was exactly the effect we sought. As "humour, most simply described, is the incongruence between what is expected and what occurs" [32], it made the mathematical pattern embedded more impressive and memorable.

Interestingly, a question addressing problem application arose in class. The students liked the mathematical pattern intertwined in Witty Peter story but doubted if they or their pupils would ever breed animals. We offered another more practical version:

Problem 6*. Each department of a starting software company consisted of four software engineers and a head. Since the business grew, for each employee an assistant was hired. Thus the number of employees totaled 360.

How many departments did the company have?

\section{Conclusions}

Adding humanities-related accents to prospective primary school teachers' mathematics classes is just one of the ways to make mathematics acceptable to a broader audience of students. Connections with literature and arts can be both engaging and effective [33-34] and through music, mathematical concepts may even sound [35-37].

According to Tabov [38], mathematics has become quite a universal discipline which brings it closer to philosophy than to science and engineering. Devlin believes that mathematics is "the science of patterns": "numerical patterns, patterns of shape, patterns of motion, patterns of behavior, voting patterns in a population, patterns of repeating chance events, and so on" [39]. It implies that for students who are predominantly interested in the humanities, mathematics based interdisciplinary projects "sharpen a viewer's eye for specific details and relationships" and "grant readers the opportunity to respond mathematically as well as historically, scientifically, and so on" [40].

Our efforts target an appropriate balance between exciting problem formulation and meaningful mathematical content. Whether we have managed to hit the bullseye one can judge from our students' reflections. Here are some of them:

N1:"My favorite subjects at school were music, Bulgarian literature, and French. I extensively studied humanities, while my science and mathematics classes were much fewer. Still, my true passion is music. Generally speaking, all the problems appealed to me. Each of them was both thought-provoking and fascinating in its own right, requiring unconventional thinking and assuming alternative solutions.

Such presentation of word problems comes in handy especially when working with children: pupils get easily absorbed in stories and it helps the teacher grab their attention. On the other hand, the kids are more likely to remember longer the algorithms studied at school. Apart from the need to be able to add and subtract, Bulgarian children must learn to love their country, mother tongue, and traditions. There is hardly a better way to preserve their Bulgarian identity.

Thanks to these problems, I realized that mathematical operations can be interesting, even entertaining. It all depends on the way the information is presented. In this case Elin Pelin provided yet another demonstration of his versatility and genius. I think he is unique."

N23: "I already know that even the word problems can be interesting!"

N17: "The word problem formulation based on plots and characters of our favorite children's stories attracts my attention, makes me follow the text and it begins to make sense to me. Then the solution comes on its own. But you have to pay attention to each detail."

The next excerpts show that the students appreciated the special place of mathematics in human knowledge. They learned that although sometimes difficult to solve, advanced problems were worth their time and efforts and paid off in the long run:

N24: "These problems taught me to use my imagination!"

N9: "Since I better understand and remember visually, the first thing I learned from solving these problems was to 
make tables or draw pictures which represented the formulation. The second thing was to concentrate on math problems. Now it may sound funny, but back then it required a lot of effort from me."

N18: "The story-based word problems were really hard, but their plots were very interesting and brought out the child in me. Their formulation stimulated my desire to solve them, even though I often failed."

The students showed genuine curiosity and even developed a suspicion to the problem details. Attracted by the opportunities to experiment and explore, they started looking at the story problems as adventures rather than challenges. Here is what students $\mathbf{L} 7$ and $\mathbf{N 2 4}$ shared:

L7: "Even if I am not sure whether I'll succeed or not, I love to toil over a problem until I solve it!"

N24: "I also want to do something similar for my pupils and make mathematical problems exciting and thought-provoking."

These thoughts make us think that we have passed the baton of our teaching ideas into the right hands. The humanities-oriented activities have helped the prospective primary school teachers build affinity to mathematics, and whenever necessary, use their acquired knowledge to make a boring math problem fun to solve.

\section{Acknowledgements}

We are sincerely grateful to Prof. Zdravko Lalchev from Sofia University "St. Kliment Ohridsky" for his support of our ideas and for giving us the opportunity to work with the students from his mathematics classes.

\section{Notes}

Figures 2 and 3 are prepared in GeoGebra Dynamic Mathematics environment [41] for educational purposes.

\section{REFERENCES}

[1] S. Tobias, C. Weissbrod. Anxiety and mathematics: An update. Harvard Educational Review, Vol. 50, No. 1, 63-70.

[2] G. M. Burton, D. Russel. Getting comfortable with mathematics. Elementary School Journal, Vol. 79, 129-135.

[3] B. J. Buhlman, D. M. Young. On the transmission of mathematics anxiety. Arithmetic Teacher, Vol. 30, No. 3, $55-56$.

[4] R. Hembree. The nature, effects, and relief of mathematics anxiety. Journal for Research in Mathematics Education, Vol. 21, 33-36.

[5] C. D. Jackson, R. G. Leffingwel. The role of instructor in creating math anxiety from kindergarten through college. Mathematics Teacher, No. 7, 583-586.

[6] K. Hadley, J. Dorward. The relationship among elementary teachers' mathematics anxiety, mathematics instructional practices, and student mathematics achievement. Journal of Curriculum and Instruction, Vol. 5, No. 2, 27-44.

[7] V. Rayner, N. Pitsolantis, H. Osana. Mathematics anxiety in preservice teachers: Its relationship to their conceptual and procedural knowledge of fractions. Mathematics Education Research Journal, Vol. 21, No. 3, 60-85.

[8] G. Haciomeroglu. Elementary pre-service teachers' mathematics anxiety and mathematics teaching anxiety. International Journal for Mathematics Teaching and Learning, 2014, 1-10.

[9] Percentage of teachers in primary education who are female. Online available from http://data.worldbank.org/indicator/ SE.PRM.TCHR.FE.ZS

[10] S. L. Beilock, E. A. Gunderson, G. Ramirez, S. C. Levine. Female teachers' math anxiety affects girls' math achievement. Proceedings of the National Academy of Sciences of the United States of America, Vol. 107, No. 5, $1860-1863$

[11] A. Mizala, F. Martínez, S. Martínez. Pre-service elementary school teachers' expectations about student performance: How their beliefs are affected by their mathematics anxiety and student's gender. Teaching and Teacher Education, Vol. $50,70-78$.

[12] L. Iossi. Strategies for reducing math anxiety in post-secondary students. Proceedings of the Sixth Annual College of Education Research Conference, Miami: Florida International University Conference, 30-35, 2007.

[13] M. Finlayson. Addressing math anxiety in the classroom. Improving Schools, Vol. 17, No. 1, 99-115.

[14] G. Polya. How to solve it, Princeton University Press, Princeton, 1957.

[15] E. L. Thorndike, M. V. Cobb, J. S. Orleans, P. M. Symons, E. Wald, E. Woodyard. The psychology of algebra, Macmillan Company, New York, 1926.

[16] P. Connoly, T. Vilardi. Writing to learn mathematics and science, Teachers College Press, New York, 1989.

[17] D. Bundy, E. Gibney, J. McColl, M. Mohlenkamp, K. Sandberg, B. Silverstein, P. Staab, M. Tearle. Good problems: teaching mathematical writing. APPM preprint \#466, University of Colorado, Denver, 2001.

[18] L. Carroll. Alice's Adventures in Wonderland. Online available from http://www.literatureproject.com/alice

[19] J. Rotschild. East Central Europe between the Two World Wars, Vol. 9, University of Washington Press, Seattle, 1974.

[20] E. Pelin, D. Podvarzachov. The Old Hand Stanyo: Story-problems, Language and Culture, Sofia, Bulgaria, 1992 (in Bulgarian).

[21] I. Gortcheva. Word problems on stage: An appealing approach to inquiry-based learning and bridge to humanities. Proceedings of the International Conference "Educational Policies in the $21^{\text {st }}$ Century”, 59-65, Center for Creative Training, Sofia, Bulgaria. 
[22] P. Assenova, E. Kelevedjiev. Informatics for $9^{\text {th }}$ grade High School Students: Compulsory Course, Regalia 6, Sofia, Bulgaria, 2001 (in Bulgarian).

[23] P. O’Daffer, R. Charles, T. Cooney, J. Dossey, J. Shielack. Mathematics for elementary school teachers, Pearson Addison Wesley, Boston, 2005.

[24] R. Zazkis, R. Leikin, S. C. Jolfaee. Contributions of "Mathematics for Elementary Teachers" Courses to Teaching: Prospective Teachers' Views and Examples. Mathematics Teacher Education and Development, Vol. 13.2, 3-21.

[25] E. Kynchev et al. Ivan Salabashev Mathematics Tournament, Unimath, Sofia, 2006.

[26] I. Gortcheva. Problem situations and inventiveness by teaching natural numbers. Mathematics and Informatics, Vol. 32, No. 5, 3-10 (in Bulgarian).

[27] M. Q. Patton. Qualitative research and evaluation methods, Sage Publications, London, 2001.

[28] C. S. Peirce. Philosophy of Mathematic: Selected Writings, Indiana University Press, Bloomington, 2010.

[29] C. Molina. The Problem with Math is English, SEDL, Hoboken, 2012.

[30] I. Gortcheva. Teaching a computer science related topic in primary school. PedActa Journal, Vol. 5, No. 1, 19-26. Online available from http://padi.psiedu.ubbcluj.ro/pedacta/article 5_1_3.pdf
[31] G. E. Andrews. Number Theory, Dover, New York, 1994

[32] R. Zazkis, P. Liljedahl. Teaching Mathematics as Storytelling, Sense Publishers, Rotterdam, 2009.

[33] J. Tabov, J. Muirhead, A. Vassileva. Dante and the humanities. The Teaching of Mathematics, Vol. II, No. 1, 31-40. Online available from http://elib.mi.sanu.ac.rs/ files/journals/tm/2/t m212.pdf

[34] H. J. Jensen. Mathematics and painting. Interdisciplinary Science Reviews, Vol. 27, No. 1, 45-49.

[35] D. Wright. Mathematics and Music, AMS, 2009.

[36] J. Fauel, R. Flood, R. Wilson (Eds.). Music and Mathematics: From Pythagoras to Fractals, Oxford University Press, New York, 2003.

[37] Mathematics \& Music. Online available from http://www. ams.org/http://www.ams.org/

[38] J. Tabov. Selection, preparation, and assessment of mathematical competitions problems: Dissertation. Institute of Matematics and Informatics, Sofia, 2004.

[39] K. Devlin. Introduction to Mathematical Thinking, Keith Devlin, Palo Alto, 2012.

[40] D. J. Whitin, P. Whitin. New Visions for Linking Literature and Mathematics, NCTE, Urbana and NCTM, Reston, 2004.

[41] Geogebra. Dynamic Mathematics for Learning and Teaching. Online available from http://www.geogebra.org/ 